\title{
Cigarette smoking in Austria - a call for action
}

\author{
David Celermajer · Subha Nasir-Ahmad
}

Received: 21 July 2017 / Accepted: 9 August 2017 / Published online: 1 September 2017

(C) Springer-Verlag GmbH Austria 2017

Smoking in Austria is prevalent and dangerous. One of the authors (DC) has recently worked as a visiting Professor of Cardiology at the University of Vienna, and noted with alarm the high smoking rates in Austria, compared to his native Australia. In Vienna and in Sydney, we treat the (avoidable) complications of smoking for the heart, on a near daily basis. As a visitor to Austria, several aspects of the smoking epidemic here are immediately obvious. Smoking rates are particularly high in young adults and remarkably, smoking is permitted indoors in bars and outdoors in restaurants, resulting in considerable "passive smoking" exposure (with significant health dangers to nonsmokers). Importantly, cigarettes are extremely cheap; approximately $€ 4.50$ per packet here verses $€ 7.50$ in Switzerland and $€ 20$ in Australia. The price of cigarettes is a key determinant of community smoking rates [1]; cheap cigarettes mean many (often heavy) smokers. Smoking prevalence in Austria was $43 \%$ of adults in 2008 versus $24 \%$ in Australia. In Austria, in 2014, approximately 1980 cigarettes were smoked per adult per year (16th highest in the world!) versus approximately 950 in Australia. The health consequences of this are potentially devastating. For example, lung cancer was the most common cause of death for men in 2013 [2] and caused nearly 400 deaths in Austria in 2014, the third most common cause of death in the country [3]. The vast majority of lung cancer is, of course, caused by smoking [4]. Equally, smoking is clearly both atherogenic and thrombogenic and

Prof. D. Celermajer ( $₫)$

Department of Cardiology, Royal Prince Alfred Hospital, Sydney, NSW, Australia

celermajer@bigpond.com

S. Nasir-Ahmad

Heart Research Institute, Sydney, NSW, Australia this is a key modifiable risk factor for myocardial infarction and stroke [5]. Less well known but now with a good evidence base, it is clear that passive smoking also accelerates heart [6] and lung diseases [7].

What can be done? Here, the Australian example is informative. Since 2008, smoking rates in Australia have fallen from $24 \%$ to $13 \%$, with likely enormous future benefits for individuals, communities and governments (via marked reductions in health care costs).

There have been two principle reasons for the substantial reductions in smoking rates in Australia; both could be easily applied in Austria. Firstly, the tax on cigarettes has been gradually and significantly increased. In 2010, a $25 \%$ increase on excise duty was introduced and in 2016 the federal budget included a $12.5 \%$ increase per year; by 2020 the cost per pack of cigarettes will be $€ 27$. Higher costs are known to discourage cigarette purchases [8], particularly by lower socioeconomic classes, who are otherwise the most vulnerable sector of the community to heart disease. The tax increases are utilized to fund the health care costs of smoking-related diseases and as a bonus, price rises dramatically reduce smoking rates.

The second initiative has been the introduction (in 2011) of plain paper packaging for cigarettes, except for health warnings. This seems to "deglamorize" smoking in the eyes of the young [9]. In Australia 85\% of the packaging highlights the health risks of smoking with graphic images as a deterrent for smokers. Austrian packaging by comparison only allocates $53 \%$ to health warnings and that only in text, thus, reducing the impact of the message. Although Australia was the first country in the world to introduce plain paper packaging, others have since followed, including the United Kingdom. Recent legal challenges by the tobacco industry against plain paper packaging have failed. 
Other measures are also possible; enhanced education efforts and reduced opportunities for tobacco-related sponsorship of sports and entertainment events. These are more ambitious and costly, but potentially very worthwhile. As concerned observers, we believe that smoking in Austria is a major problem but with (at least two) proven solutions that can be easily implemented; a tax strategy and a plain packaging policy. Both work, both save lives and neither infringes civil liberties. The time for action is now; the opportunity to save tens of thousands of lives in future years is too important to miss.

Conflict of interest D. Celermajer and S. Nasir-Ahmad declare that they have no competing interests.

\section{References}

1. Calo WA, Krasny S. Environmental determinants of smoking behaviors: the role of policy and environmental interventions in preventing smoking initiation and supporting cessation. Curr Cardiovasc Risk Reports. 2013;7(6):446-52.

2. Ferlay J, Steliarova-Foucher E, Lortet-Tieulent J, Rosso S, Coebergh JW, Comber H, Forman D, Bray F. Cancer incidence and mortality patterns in Europe: estimates for 40 countries in 2012. Eur J Cancer. 2013;49(6):1374-403.
3. Thompson CA, Waldhör T, Schernhammer ES, Hackl M, Vutuc C, Haidinger G. Smoking and lung cancer: current trends in Austria. Wien Klin Wochenschr. 2012;124(15-16):493-9.

4. Flanders WD, Lally CA, Zhu BP, Henley SJ, Thun MJ. Lung cancer mortality in relation to age, duration of smoking, and daily cigarette consumption. Cancer Res. 2003;63(19):6556-62.

5. Centers for Disease Control and Prevention (US); National Center for Chronic Disease Prevention and Health Promotion (US); Office on Smoking and Health (US). How Tobacco Smoke Causes Disease: The Biology and Behavioral Basis for Smoking-Attributable Disease: A Report of the Surgeon General. Atlanta GA: Centers for Disease Control and Prevention(US);2010.

6. Prugger C, Wellmann J, Heidrich J, De Bacquer D, Perier MC, Empana JP, Reiner Ž, Fras Z, Jennings C, Kotseva K, Wood D. Passive smoking and smoking cessation among patients with coronary heart disease across Europe: results from the EUROASPIRE III survey. Eur HeartJ. 2013;35(9):590-8.

7. Hagstad S, Bjerg A, Ekerljung L, Backman H, Lindberg A, Rönmark E, Lundbäck B. Passive smoking exposure is associated with increased risk of COPD in never smokers. Chest. 2014;145(6):1298-304.

8. Bader P, Boisclair D, Ferrence R. Effects of tobacco taxation and pricing on smoking behavior in high risk populations: a knowledge synthesis. Int J Environ Res Public Health. 2011;8(11):4118-39.

9. Erickson M, Mackay J, Schluger N, editors. The Tobacco Atlas. Georgia: American Cancer Society; 2015. 